\title{
Diabetic Muscle Infarction: A Rare End-Organ Vascular Complication of Diabetes
}

Callie Seaman, BS ${ }^{1}$, Michael Amos, MD ${ }^{1}$, Adam M. Franks, MD1, Asher Sexton, MD'1, Kimberly McClelland, MD, MPH, MBA ${ }^{1}$, Erika M. Harris, MD¹

ABSTRACT

Diabetic muscle infarction (DMI) is a rare microvascular complication of spontaneous ischemic necrosis of skeletal muscle in patients with poorly controlled diabetes. We herein describe the case of a 26-year-old woman with a history of type I diabetes and accompanying diabetic microvascular complications of neuropathy, nephropathy and retinopathy, who presented with sudden onset of swelling and sharp pain in her bilateral thighs. T2-weighted MRI imaging revealed subcutaneous edema and subfascial, hyper-intense enhancement of proximal thigh musculature. DMI has a relatively non-specific clinical presentation; therefore, physician awareness is key for early diagnosis, as aggressive management has been associated with poor patient outcomes. With poor long-term prognosis and high reoccurrence, DMI acts as an indicator of vascular end-organ damage.
Author affiliations are listed at the end of this article.

Correspondence to: Adam M. Franks, MD Marshall Unviersity Joan C. Edwards School of Medicine franks1@marshall.edu

\section{KEYWORDS}

Diabetic Muscle Infarction, Diabetic Myonecrosis

\section{INTRODUCTION}

Diabetic muscle infarction (DMI) is a rare microvascular complication consisting of spontaneous ischemic necrosis of skeletal muscle in patients with poorly controlled diabetes. Though its characteristics have been defined, fewer than 200 cases $^{1,2}$ have been reported since it was first described in 1965 by Angervall and Stener. ${ }^{3}$ Originally, it was termed "tumoriform focal muscular degeneration," owing to the initial cases' resemblance to tumors, which in that case were completely excised. ${ }^{1,3-7}$ The condition has also known as diabetic, aseptic, or ischemic myonecrosis.

DMI can occur in patients with either type 1 or 2 diabetes, with type 1 representing around 70\% of cases..$^{7-10}$ Affected patients have a history of long-standing (>15 years) and poorly controlled diabetes (average $\mathrm{Hgb}$ a1c of $9.4 \%$ with a range of $5.0 \%$ to $12.4 \%),{ }^{2,4,5,9-16}$ with a mean age of 43

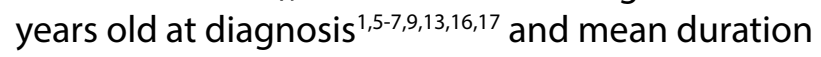
between diagnosis of diabetes and DMI around 14.4 years. $5,710,13,17$ There seems to be a slight predilection towards females. ${ }^{1,5,7,11,13}$ Nearly $97 \% \%^{9,13}$ of patients present with end-organ diabetic microvascular complications s, 11,14 including nephropathy (57\%), retinopathy (71\%) and neuropathy (55\%). ${ }^{4-7,16,17}$

Due to the rarity of the disease and many alternative etiologies for the symptoms, DMI is often under-recognized, leading to delayed diagnosis, inappropriate treatment, and excessive lab and radiographic testing. 5,6,8,10 In this case, a 26-year-old woman with type 1 diabetes mellitus presents with DMI and affords a discussion of clinical features, diagnosis and pathogenesis of DMI.

\section{CASE PRESENTATION}

At 26 years of age, a non-smoking type 1 diabetic patient with neuropathy, nephropathy, and retinopathy presented to her primary care physician from a local emergency room with a seven-day history of sudden swelling followed by a sharp pain in her bilateral thighs that initially occurred during a hike in the woods. The pain was constant and limited 
her range of motion, making ambulation difficult. No erythema, focal warmth or masses were appreciable. Her vital signs were stable, and she was afebrile. Her white blood cell count was $9.9 \mathrm{k} / \mathrm{mm} 3$ (range: $5-10 \mathrm{k} /$ $\mathrm{mm} 3$ ) with $82.4 \%$ neutrophils. The chemistry profile demonstrated a creatinine of $3.6 \mathrm{mg} / \mathrm{dL}$ and glucose of $157 \mathrm{mg} / \mathrm{dL}$. Hgb a1c was 10.4\% (normal: < 7\%). Erythrocyte sedimentation rate (ESR) was elevated at $140 \mathrm{~mm} / \mathrm{hr}$ (normal: 0-20 mm/hr), as were creatine phosphokinase (CPK) and serum myoglobin at 259 $\mathrm{U} / \mathrm{L}$ (normal: 30-135 U/L) and $413 \mathrm{ng} / \mathrm{dL}$ (normal: 0-110 $\mathrm{ng} / \mathrm{dL}$ ) respectively. $\mathrm{D}$-dimer was positive at 5.1 $\mathrm{mg} / \mathrm{L}$ (normal: $0.200-2.18 \mathrm{mg} / \mathrm{L}$ ), but her subsequent venous ultrasound ruled out lower extremity deep venous thrombosis (DVT). A presumptive diagnosis of cellulitis was initially given, and she was treated with ciprofloxacin.

One week later, as the pain and edema increased, she was no longer ambulatory despite improving ESR (109 mm/hr), CPK (151 U/L) and myoglobin (280 $\mathrm{ng} / \mathrm{dL}$ ). T2-weighted MRI images showed diffuse subcutaneous edema as well as sub-fascial and hyperintense enhancement of the adductor brevis, magnus, and longus. Some involvement of the upper gracilis was also noted, and the patient was placed on bed rest. Two weeks later, she was hospitalized for acute renal failure, but her painful, edematous thighs persisted. Upon admission her ESR was 40 $\mathrm{mm} / \mathrm{hr}, C P K$ was $74 \mathrm{U} / \mathrm{L}$, and myoglobin was $214 \mathrm{ng} /$ $\mathrm{dL}$. Swelling and pain persisted throughout that and a second admission for acute renal failure. Because of the probable diagnosis of DMI, a muscle biopsy was not performed. With the treatment of only bed rest, pain control with non-steroidal anti-inflammatory medications (NSAIDs) and narcotics, symptoms resolved spontaneously within six weeks. Table 1 demonstrates the patient's demographic and clinical parameters compared to the accumulated ranges reported in the literature.

The patient's chronic renal failure worsened, and within a month she was placed on peritoneal dialysis before having a simultaneous kidney-pancreas transplant four months later. Her postoperative course was complicated by an abdominal hematoma that needed to be evacuated. She also suffered a CVA with right-sided hemiparesis that led to seizures. Two and a half months from her transplant she succumbed to vancomycin-resistant enterococci
(VRE) sepsis secondary to pneumonia and pyelonephritis.

\section{DISCUSSION}

The findings suggestive of DMI in this patient begin with her spontaneous acute muscular pain, markedly in her thighs, with no history of trauma or indication of infection. 1,25,7,9-11,15,18 The severe pain, even at rest, was exacerbated by movement, which limited her mobility. ${ }^{8,11,12,14,17,19,20} \mathrm{DMl}$ usually presents unilaterally $4,10,18$ in the proximal lower extremity (81-83\%) with rare reports of distal leg involvement. $2,5,8,11,14,19,20$ Muscles commonly affected include quadriceps $(60 \%), 4,10,16,18$ hip adductors (13\%), $4,10,11,14,16$ hamstrings $(8 \%)^{4,10,16,18}$ and hip flexors (2\%).,10,16 Patients are typically afebrile, without skin discoloration, ${ }^{9,11,20}$ and usually present with accompanying local swelling (90\%-99\%), $1,2,4,5,7-13,16-20$ tenderness, ${ }^{1,2,4-10,12,13,15-19}$ and painful, palpable mass (44\%). $2,6,7,9,11-14,17-20$

DMI is frequently misdiagnosed because of the significant overlap of its clinical features with other life- and limb-threatening etiologies, and there remains no clear consensus of diagnostic criteria. ${ }^{1,6,15}$ Differential diagnoses considerations are extensive (Table 2). Currently, diagnosis of DMI consists of a clinical assessment and MRI. ${ }^{5-7,19}$ Muscle biopsies, revealing some combination of monocytic inflammation, hemorrhagic necrosis, fibrosis, atrophy, and neovascularization, are the gold standard, carrying 90\% sensitivity and 95\% sensitivity ${ }^{19}$, and are not recommended because of procedural complications, including delayed healing and infection. ${ }^{1,2,-7,10,15,16,19}$ If attempted, a minimally invasive approach is recommended, which should be reserved for patients with an atypical presentation, uncertain diagnosis, or those that do not improve with treatment. ${ }^{2,7,15,19}$

MRI with T2-weighted imaging is the most valuable diagnostic imaging method, carrying a sensitivity close to $100 \%,{ }^{1,2,6,8-11,13,15,17,19}$ with hyperintense images of subfascial fluid from edema and hemorrhage with enlargement of defined muscles (Picture 1). 2,4,5,7,10,11,13,14,20 This contrasts with T1-weighted images, which would show water content from edema and water content as hypointense. ${ }^{2,710,13,15,20}$ Other radiographic 
Diabetic Myonecrosis Trends \& Comparison to Case Patient

\begin{tabular}{|c|c|c|}
\hline Demographics & Range & Case Patient \\
\hline Gender & $54 \%-66 \%$ Female & Female \\
\hline Age & $40-49$ yo & 26 yo \\
\hline Diabetes, type 1 & $41.5 \%-75 \%$ & Yes \\
\hline $\mathrm{Hgb}$ alc & $5.0-12.4 \%$ & 10.4 \\
\hline Years since Diabetes Diagnosed & $14.4-17$ years & 17 years \\
\hline Diabetes Complications & $97 \%$ & Yes \\
\hline Nephropathy & $57 \%-71 \%$ & Yes \\
\hline Retinopathy & $57 \%-71 \%$ & Yes \\
\hline Neuropathy & $55 \%-75 \%$ & Yes \\
\hline \multicolumn{3}{|l|}{ Symptoms } \\
\hline Acute & Universal & Yes \\
\hline Local Swelling & $75.6 \%-99 \%$ & Yes \\
\hline Tendemess & $80 \%-100 \%$ & Yes \\
\hline Palpable Mass & $33.7 \%-44 \%$ & No \\
\hline Lack of Fever & $89 \%$ & Yes \\
\hline Limited ROM & Worse with movement & Yes \\
\hline Erythema & Not Common & No \\
\hline Edema & Common & Yes \\
\hline Unilateral & $60 \%-91.6 \%$ & Bilateral \\
\hline Proximal & $66.7 \%-87 \%$ & Yes \\
\hline \multicolumn{3}{|l|}{ Muscle Groups } \\
\hline Quadriceps & $60 \%-87 \%$ & No \\
\hline Hip Adductors & $13 \%$ & Yes \\
\hline Hamstrings & $8 \%$ & No \\
\hline Hip Flexors & $2 \%$ & No \\
\hline Calf & $13 \%-22.9 \%$ & No \\
\hline Multiple & $39 \%$ & Multiple \\
\hline \multicolumn{3}{|l|}{ Diagnosis } \\
\hline Erythrocyte Sedimentation Rate & increased $31.4 \%-88.9 \%$ & 140 \\
\hline Creatinine Phosphokinase & increased $81.8 \%-90 \%$ & 259 \\
\hline Myoglobin & increased $81.8 \%-90 \%$ & 413 \\
\hline White Blood Cells & increase $8 \%-56.6 \%$ & 9.94 \\
\hline Blood Culture & Negative & Negative \\
\hline Ultrasound & Useful to rule out DVT & ruled out DVT \\
\hline T2-Weighted MRI & Hyperintense = necrosis, edema \& subfascial fluid & Hyperintense \\
\hline Muscle Biopsy & Monocytic infiltration, necrosis, and fibrosis & Not Done \\
\hline \multicolumn{3}{|l|}{ Prognosis } \\
\hline Resolution & 6 to 8 weeks & 9 weeks \\
\hline Recurrence & $40-50 \%$ & Did not recur \\
\hline Mortality & $10 \%$ Mortality Rate within 2 years & Died 7.5 months later \\
\hline
\end{tabular}

TABLE 1: Denotes the consensus of demographics, signs and symptoms and diagnostic results of reported patients with diabetic muscle infarction and compares them to the case-patient. 


\begin{tabular}{|c|c|c|c|c|}
\hline \multicolumn{5}{|c|}{ Diabetic Muscle Infarction Differential Diagnoses } \\
\hline Infectious & Inflammatory & Malignancy & Musculoskeletal & Vascular \\
\hline Abscess & Dermatomyositis & Benign Tumors & $\begin{array}{l}\text { Acute } \\
\text { Arthropathy }\end{array}$ & $\begin{array}{l}\text { Compartment } \\
\text { Syndrome }\end{array}$ \\
\hline Cellulitis & Polymyositis & Lymphoma & $\begin{array}{l}\text { Baker's Cyst } \\
\text { Rupture }\end{array}$ & DVT \\
\hline $\begin{array}{l}\text { Necrotizing } \\
\text { Fasciitis }\end{array}$ & Pyomyositis & $\begin{array}{l}\text { Metastatic } \\
\text { Tumors }\end{array}$ & $\begin{array}{l}\text { Diabetic } \\
\text { Amyotrophy }\end{array}$ & Hematoma \\
\hline Osteomyelitis & \multirow{3}{*}{$\begin{array}{l}\text { Other: } \\
\text { - Focal } \\
\text { - Nodular } \\
\text { - Proliferative }\end{array}$} & \multirow[t]{3}{*}{ Sarcoma } & Muscle Rupture & Thrombophlebitis \\
\hline \multirow[t]{2}{*}{ Parasitic Infection } & & & Statin-Induced & \multirow[t]{2}{*}{ Vasculitis } \\
\hline & & & Trauma & \\
\hline
\end{tabular}

TABLE 2: Categorization of the diagnoses in the differential for diabetic muscle infarction. (DVT = deep venous thrombosis. Diabetic amyotrophy is also known as diabetic lumbosacral radiculoplexus neuropathy, proximal diabetic neuropathy, and diabetic polyradiculoneuropathy)

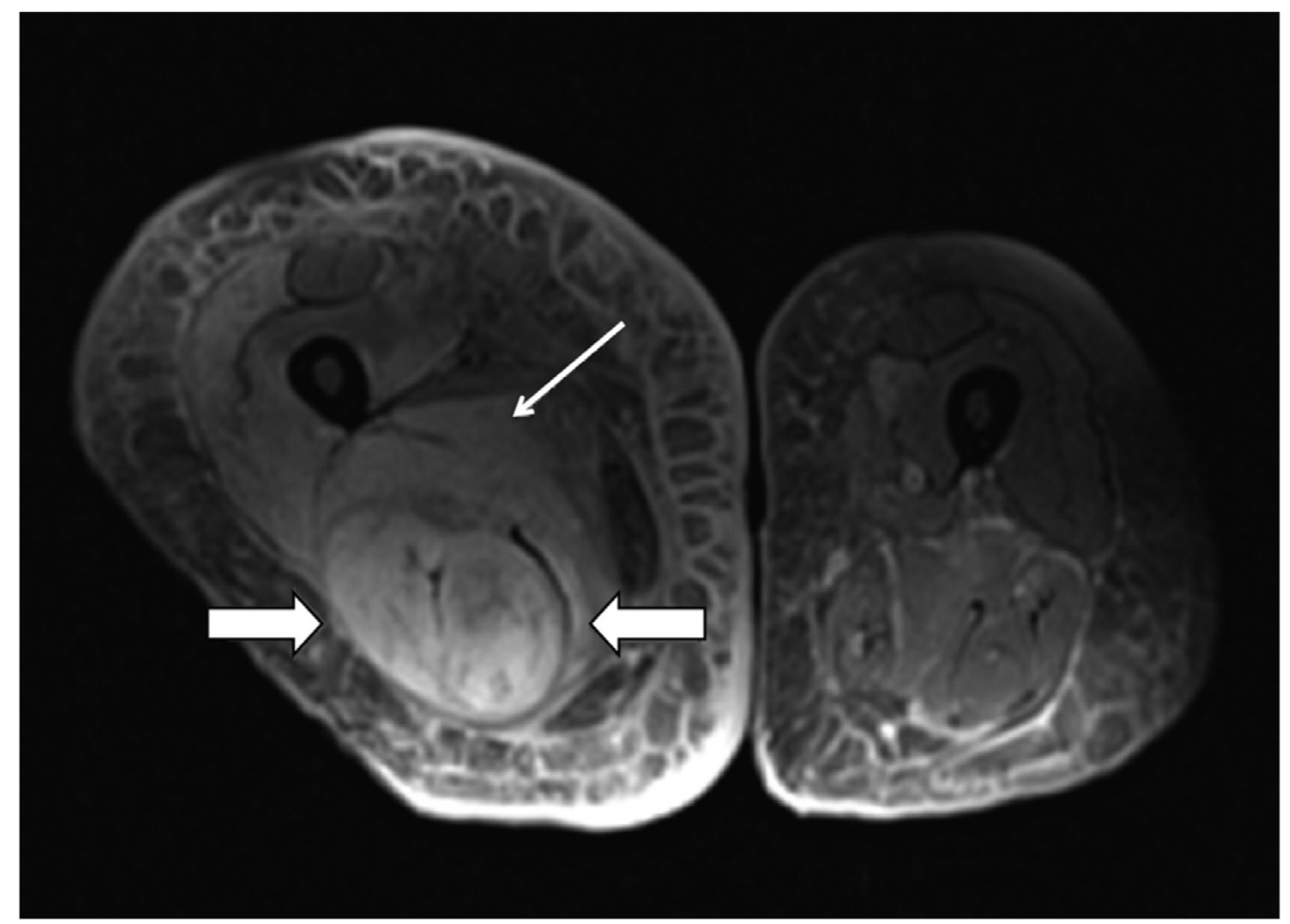

PICTURE 1: Proton density fat-saturated MRI showing increased signal within the semimembranosus, biceps femoris, and adductor magnus musculature that is found to be consistent with edema due to early muscle infarction. ${ }^{1}$ 
techniques, such as ultrasound and CT, are not considered satisfactory to confirm the diagnosis but are useful for excluding other disorders.7,9 In contrast to imaging, there is a lack of consistency in lab findings. ${ }^{5-7,10}$ White blood cell counts, CPK levels, and inflammatory markers may be normal to elevated. ${ }^{2,6,7,9,14,15,18} \mathrm{It}$ is suggested CPK is elevated during the early presentation and falls to normal levels later in the disease course. ${ }^{17}$ Patients' delay in seeking medical attention, approximately four weeks on average, may prevent the detection of these changes and likely account for the variation of finding in the literature. ${ }^{5,7}$ Table 3 demonstrates the laboratory and physical exam variations in the case-patient. This trend seems to correlate with the variability of a necrosis-reperfusion process and has not yet been explored in the literature.
The literature predominately laments that the pathophysiology of DMI is not well understood, and more research is needed. . $2,5,8-10,12$ Patient $^{2}$ history, clinical presentation, histological features, and radiographic imaging seem to point to a unifying theory of a microangiopathic vascular complication. ${ }^{1,5,7,9-12,15,16,18,19} \mathrm{~A}$ cascade initiated by microvascular endothelial damage leads to tissue ischemia activating inflammatory cascade causing local tissue damage. This damage is followed by the focal replacement of the infarcted muscle with collagen (Picture 2). Reperfusion occurs, resulting in impaired endothelial-dependent dilation of arterioles, increased oxygen radicals, and decreased nitric oxide leading to further injury. ${ }^{1,5,11}$ Increased edema creates intra-compartmental pressure, decreasing blood flow further creating ischemia from

\begin{tabular}{|c|c|c|c|c|c|c|c|c|}
\hline \multicolumn{9}{|c|}{ Case Patient Lab Trends and Physical Exam Findings } \\
\hline & & & Onset & Day 8 & Day 13 & Day 18 & Day 68 & \\
\hline Lab Test & Normal & DMI Trend & ED & 1st Visit & Follow-up & Hospital & Recovery & Trend \\
\hline WBC & $5-10 \mathrm{k} / \mathrm{mm}^{3}$ & increased $8 \%-56.6 \%$ & 9.94 & 12.3 & & 9.2 & 7.46 & Variable \\
\hline ESR & $0-20 \mathrm{~mm} / \mathrm{hr}$ & $\begin{array}{c}\text { increased } 31.4 \%- \\
88.9 \% \\
\end{array}$ & 140 & 109 & & 40 & & Descending \\
\hline CPK & $30-135 \mathrm{U} / \mathrm{L}$ & increased $81.8 \%-90 \%$ & 259 & 151 & 215 & 74 & 133 & Variable \\
\hline Myoglobin & $0-110 \mathrm{ng} / \mathrm{dL}$ & increased $81.8 \%-90 \%$ & 413 & 280 & 251 & 214 & 206 & Descending \\
\hline Physical Exam Findings & & & ED & 1st Visit & Follow-up & Hospital & Recovery & \\
\hline Leg Swelling & & & Yes & Increased & Stable & Continued & Improved & \\
\hline Leg Pain & & & Yes & Increased & Stable & Continued & Improved & \\
\hline Weakness & & & Yes & Increased & Stable & Continued & Improved & \\
\hline
\end{tabular}

TABLE 3: Comparison of the trend in lab work for the case patient over time in relation to symptoms. (WBC $=$ white blood count, ESR = erythrocyte sedimentation rate, $\mathrm{CPK}=$ creatinine phosphokinase)

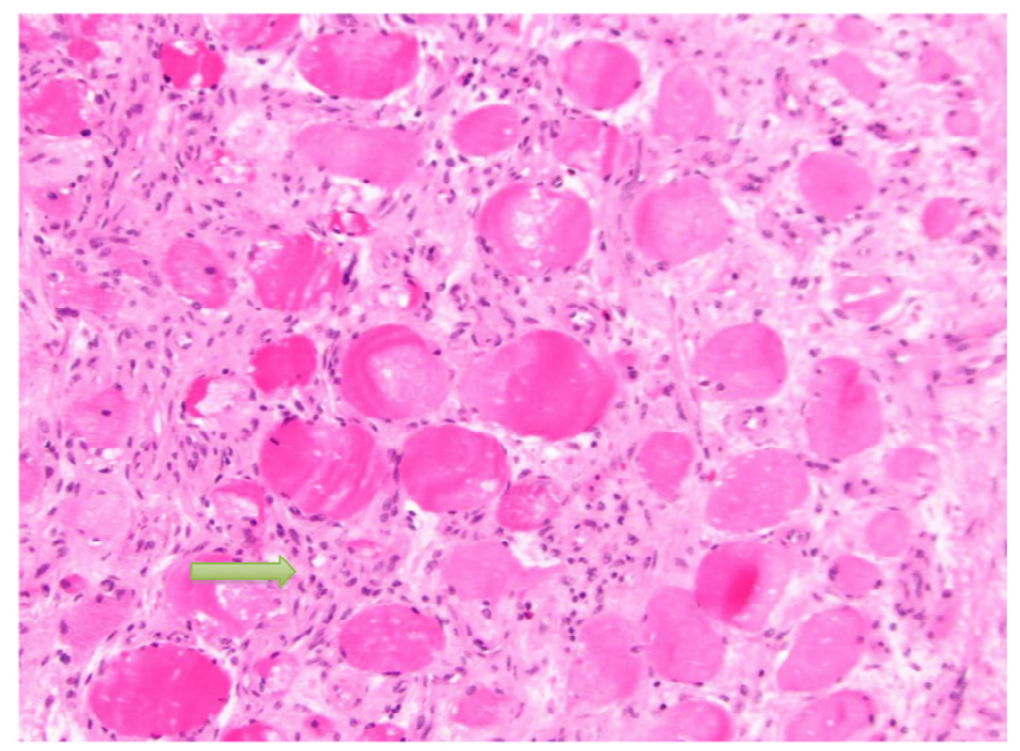

PICTURE 2: Histologic Slide of a Diabetic Muscle Infarction biopsy under H\&E stain. Macrocytic invasion is seen along with the collagenous replacement of infarcted tissue. ${ }^{4}$ 
compartment syndrome. ${ }^{1,5,7,17}$ Muscle regeneration occurs as well and may be seen histologically at time of care. ${ }^{11}$

Early recognition of DMI is important to avoid inappropriate treatment. ${ }^{2,5,10,11,17}$ Current recommendations are based on limited evidence ${ }^{1,19}$ and consist mainly of supportive care, $, 4,5,8-10,13-16,18,20$ including bed rest combined with aspirin and NSAIDS. 1,2,4,6-11,13-18,20 Perhaps the most important intervention, however, is rigorous glycemic control. Hyperglycemia may contribute to DMI by affecting the remodeling of vasculature, platelet function, and coagulation factors. ${ }^{6}$ Surgical intervention is not recommended and has shown poor outcomes with increased recovery time, risk of infection, hematoma, nerve palsy, sepsis, and compartment syndrome. ${ }^{1,4,8,10,15,17,20}$ Physical therapy should be avoided in the acute phase as muscle stretching can increase pain and swelling, ultimately prolonging recovery, but may have a place in care following the acute injury. ${ }^{1,5-8,14,17}$

One should view the prognosis rates as similar to a patient with a myocardial infarction. ${ }^{2}$ Short-term prognosis of the patients is good, and a majority make a full recovery with spontaneous resolution of symptoms within weeks to months. ${ }^{2,5,9,10,17}$ However, patients are at high risk of reoccurrence $(\sim 50 \%))^{1,12}$ within the original muscle $(8.7 \%)^{7,9}$ or a different muscle group (40\%).8,10,16 Unfortunately, the long-term prognosis is poor, as most patients die within 2-5 years of diagnosis. ${ }^{2,6,7,9,10}$ The presence of DMl acts as an indicator suggestive of endorgan vasculopathy, and patients should undergo evaluation for other vascular damage. ${ }^{9}$

\section{CONCLUSION}

The overall literature on DMI is small and the publications have a significant overlap in findings. While the prevailing principles for presentation, diagnosis, and management are in general agreement, the small individual cohorts lend themselves to wide variability in specific percentages. Making sense of proper diagnostic and management principles is important, as more aggressive options have deleterious effects. Clearly, overall, DMI is a harbinger of vascular end-organ damage and should be treated as such.

\section{AUTHOR AFFILIATIONS}

1. Marshall University Joan C. Edwards School of Medicine, Huntington, West Virginia

\section{REFERENCES}

1. Horton WB, Taylor JS, Ragland TJ, Subauste AR. Diabetic muscle infarction: a systematic review. BMJ Open Diabetes Research \& Care. 2015;3(1).

2. Chebbi W, Jerbi S, Klii R, et al. Multifocal diabetic muscle infarction: a rare complication of poorly controlled diabetes mellitus. Internal Medicine. 2014;53(18):2091-2094.

3. Angervall $L$, Stener B. Tumoriform focal muscular degeneration in two diabetic patients. Diabetologia. 1965;1(1):39-42.

4. Bhasin R, Ghobrial I. Diabetic myonecrosis: a diagnostic challenge in patients with longstanding diabetes. Journal of Community Hospital Internal Medicine Perspectives. 2013;3(1):20494.

5. Yong TY, Khow KSF. Diabetic muscle infarction in end-stage renal disease: A scoping review on epidemiology, diagnosis and treatment. World Journal of Nephrology. 2018;7(2):58-64.

6. Cumberledge J, Kumar B, Rudy D. Risking life and limb: a case of spontaneous diabetic muscle infarction (diabetic myonecrosis). Journal of General Internal Medicine. 2015;31(6):696-698.

7. Trujillo-Santos AJ. Diabetic muscle infarction: an underdiagnosed complication of long-standing diabetes. Diabetes Care. 2003;26(1):211-215.

8. Parmar MS. Diabetic muscle infarction. BMJ. 2009;338:b2271.

9. Mathew A, Reddy S, Archibald C. Diabetic muscle infarction. Case Reports. 2009.

10. Khanna HK, Stevens AC. Diabetic Myonecrosis: A rare complication of diabetes mellitus mimicking deep vein thrombosis. American Journal of Case Reports. 2017;18:38-41.

11. Umpierrez GE, Stiles RG, Kleinbart J, Krendel DA, Watts NB. Diabetic muscle infarction. The American Journal of Medicine. 1996;101(3):245250.

12. Delaney-Sathy LO, Fessell DP, Jacobson JA, 
Hayes CW. Sonography of diabetic muscle infarction with MR Imaging, $\mathrm{CT}$, and pathologic correlation. American Journal of Roentgenology. 2000;174(1):165-169.

13. Saikia U, Saikia M, Bhuyan D, Choudhury B, Sarma D, Choudhury S. Diabetic myonecrosis: an underreported complication of diabetes mellitus. Indian Journal of Endocrinology and Metabolism. 2011;15(5):58.

14. Bunch MTJ, Birskovich MLM, Eiken MPW. Diabetic myonecrosis in a previously healthy woman and review of a 25-Year Mayo Clinic experience. Endocrine Practice. 2002;8(5):343-346.

15. Janga KC, Sinha A, Wengrofsky $P$, et al.

Diabetic muscle infarction masquerading as necrotizing fasciitis. Case Reports in Nephrology. 2017;2017:1-3.

16. Mukherjee S, Aggarwal A, Rastogi A, et al. Spontaneous diabetic myonecrosis: report of four cases from a tertiary care institute. Endocrinology, Diabetes \& Metabolism Case Reports. 2015;2015.

17. Vlieger GD, Bammens B, Claus F, Vos R, Claes K. Diabetic muscle infarction: a rare cause of acute limb pain in dialysis patients. Case Reports in Nephrology. 2013;2013:1-6.

18. MacGregor JL, Chan PC, Schneiderman, Grossman ME. Diabetic muscle infarction. Archives of Dermatology. 2007;143(11):1456-7.

19. Shenavandeh $S$, Anushiravani A, Nazarinia $M$. Diabetic muscle infarction and diabetic dermopathy two manifestations of uncontrolled prolong diabetes mellitus presenting with severe leg pain and leg skin lesions. Journal of Diabetes \& Metabolic Disorders. 2014;13(1):38.

20. Uçan H, Alemdaroğlu E, Yoldaş TK, Özdamar SE, Akyüz M, Hatipoğlu C. Diabetic muscular infarct: an unusual cause of extremity pain and dysfunction. Rheumatology International. 2011;32(2):525-528. 